\title{
Internal drainage versus external drainage in palliation of malignant biliary obstruction: a meta-analysis and systematic review
}

\author{
Xiaopeng Tian ${ }^{1,2}$, Zixuan Zhang ${ }^{1}$, Wen $\mathrm{Li}^{1,3}$
}

\author{
${ }^{1}$ Medical School of Chinese PLA, Beijing, China \\ 2Department of Gastroenterology, Xingtai People's Hospital, Xingtai, Hebei, China \\ ${ }^{3}$ Department of Gastroenterology and Hepatology, Chinese PLA General Hospital, \\ Beijing, China
}

Submitted: 24 July 2017

Accepted: 2 November 2017

Arch Med Sci 2020; 16 (4): 752-763

DOI: https://doi.org/10.5114/aoms.2020.94160

Copyright (c) 2020 Termedia \& Banach

\section{Abstract}

Introduction: Preoperative biliary drainage has been widely used to treat patients with malignant biliary obstruction. However, it is still unclear which method is more effective: internal drainage or external drainage. Thus, we carried out a meta-analysis to compare the safety and efficacy of the two drainage methods in treatment of malignant biliary obstruction in terms of preoperative and postoperative complications.

Material and methods: We conducted a literature search of Medline, EMBASE, PubMed, Ovid journals and the Cochrane Library, and compared internal drainage and external drainage in malignant biliary obstruction patients. The pre- and postoperative complications, stent dysfunction rate and mortality were analyzed.

Results: Ten published studies ( $n=1464$ patients) were included in this metaanalysis. We found that patients with malignant biliary obstruction who received external drainage showed reductions in the preoperative cholangitis rate $(\mathrm{OR}=0.33,95 \% \mathrm{Cl}: 0.24-0.44, p<0.00001)$, the incidence of stent dysfunction ( $\mathrm{OR}=0.41,95 \% \mathrm{Cl}: 0.30-0.57, p<0.00001)$, and total morbidity $(\mathrm{OR}=0.34,95 \% \mathrm{Cl}: 0.23-0.50, p<0.00001)$ compared with patients who received internal drainage.

Conclusions: The current meta-analysis indicates that external drainage is better than internal drainage for malignant biliary obstruction in terms of the preoperative cholangitis rate, the incidence of stent dysfunction and total morbidity, etc. However, the findings need to be confirmed by randomized controlled trials.

Key words: malignant biliary obstruction, preoperative biliary drainage, internal drainage, external drainage, meta-analysis.

\section{Introduction}

Malignant biliary obstruction (MBO) is a common disease in the clinic that may be caused by the compression and invasion of malignant tumors or metastatic lymph nodes to biliary ducts. Common malignant tumors include primary carcinoma of the bile duct, gallbladder carcinoma, liver cancer, carcinoma of the head of the pancreas, ampullary carcinoma and other metastatic cancers. MBO has a poor prognosis, and its 5 -year survival rate is estimated to be less than $5 \%$ [1]. Surgery should

\author{
Corresponding author: \\ Wen Li \\ Department \\ of Gastroenterology \\ and Hepatology \\ Chinese PLA General Hospital \\ Medical School of Chinese PLA \\ 28 Fuxing Road \\ Beijing 100853, China \\ Phone: +861055499107 \\ E-mail: liwen2000@yahoo.com
}


be the first choice of treatment for such patients, and the traditional method is to carry out tumor resection combined with choledochojejunostomy. However, those patients usually have severe jaundice when visiting the hospital. Some of them are suffering from severe cholangitis on the basis of jaundice, indicating a serious state of illness and poor systemic condition, which may result in an extremely low resection rate. In addition, patients may suffer relatively high postoperative complications and mortality. Even worse, some of the patients cannot tolerate palliative biliary tract decompression. With respect to the above, preoperative biliary drainage has been widely accepted in clinical practice and is used to decrease the severity of jaundice, thereby improving the prognosis of patients [2]. However, preoperative biliary drainage is still controversial in clinical practice $[3,4]$. One of the major problems is that preoperative biliary drainage may lead to biliary drainage-related complications such as cholangitis, pancreatitis, hemorrhage, or perforation. Moreover, biliary drainage-related complications may introduce postoperative complications. Therefore, the selection and application of an appropriate method for drainage that is safer and more effective is an urgent problem to be solved. At present, there are two commonly used drainage methods: external drainage and internal drainage. External drainage mainly consists of percutaneous transhepatic biliary drainage (PTBD) and endoscopic nasobiliary drainage (ENBD), while internal drainage is predominantly endoscopic bile duct stenting (EBS). So far, it remains unclear whether internal drainage or external drainage is more appropriate for preoperative biliary drainage. Therefore, the present study was conducted to evaluate and compare the efficacy and safety of the two drainage methods in MBO treatment in terms of preoperative and postoperative complications, so as to provide a potential basis for clinical treatment options.

\section{Material and methods}

\section{Search strategy}

Two researchers conducted a literature search of the Medline, EMBASE, PubMed, Ovid journals and Cochrane Library databases to identify relevant available articles published in English between January 1980 and May 2017. The search strategy involved keyword search and subject headings retrieval. The search terms included "external drainage" or "nasobiliary drainage", "ENBD” or "percutaneous transhepatic biliary drainage", "PTBD" combined with the terms "internal drainage" or "endoscopic biliary stenting", "EBS", "endoscopic retrograde biliary drainage”, "ERBD”. A preliminary selection was conducted by screening titles and abstracts of the retrieved literature. Documents that met the inclusion criteria were then checked carefully in full detail to finally determine whether or not to incorporate them. To avoid missing useful information, we also reviewed the reference lists of the included studies for undetected relevant studies and contacted the original authors to obtain extra information if necessary.

\section{Inclusion criteria}

The inclusion criteria were as follows: included studies focused on the assessment of preoperative biliary drainage in patients with malignant biliary obstruction; the drainage methods were external drainage (PTBD or ENBD) and internal drainage (EBS); the outcomes included pre- and post-operative complications; original research from observational studies or randomized controlled trials. Two investigators searched and reviewed all identified studies independently. If the 2 investigators could not reach a consensus about the eligibility of an article, it was resolved by consulting a third reviewer.

\section{Exclusion criteria}

Subjects included in the study were patients with benign obstructive jaundice, or patients who were unable to undergo surgical treatment; the drainage method was only external drainage or internal drainage; repeated reports; the design was flawed, and the quality of the study was poor.

\section{Data extraction and quality assessment}

The following data were independently extracted from each study by 2 investigators: the first author's name, the publication year, the study design, the size of the drainage tube, the age range or mean age at baseline, pre- and postoperative complications, stent/tube dysfunction and mortality. Stent/tube dysfunction (occlusion or dislocation) is defined as the recurrence of biliary obstruction and jaundice and/or evidence of cholestasis confirmed by ultrasonography (US) or computed tomography (CT), requiring biliary re-intervention. The Newcastle-Ottawa Scale, an instrument for evaluating the quality of observational studies, was used to assess each of the included studies [5]. Each study was awarded a score of 1 point to 9 points (Table I).

\section{Statistical analysis}

When included studies were comparable, metaanalysis was performed, otherwise systematic review was conducted only. Dichotomous data are presented as the odds ratio (OR) with 95\% confidence interval $(\mathrm{Cl})$. The heterogeneity among studies was tested using a $\chi^{2}$-based $Q$ test. If there was no significant heterogeneity $(p>0.10)$, the fixed effect model was applied for follow-up 


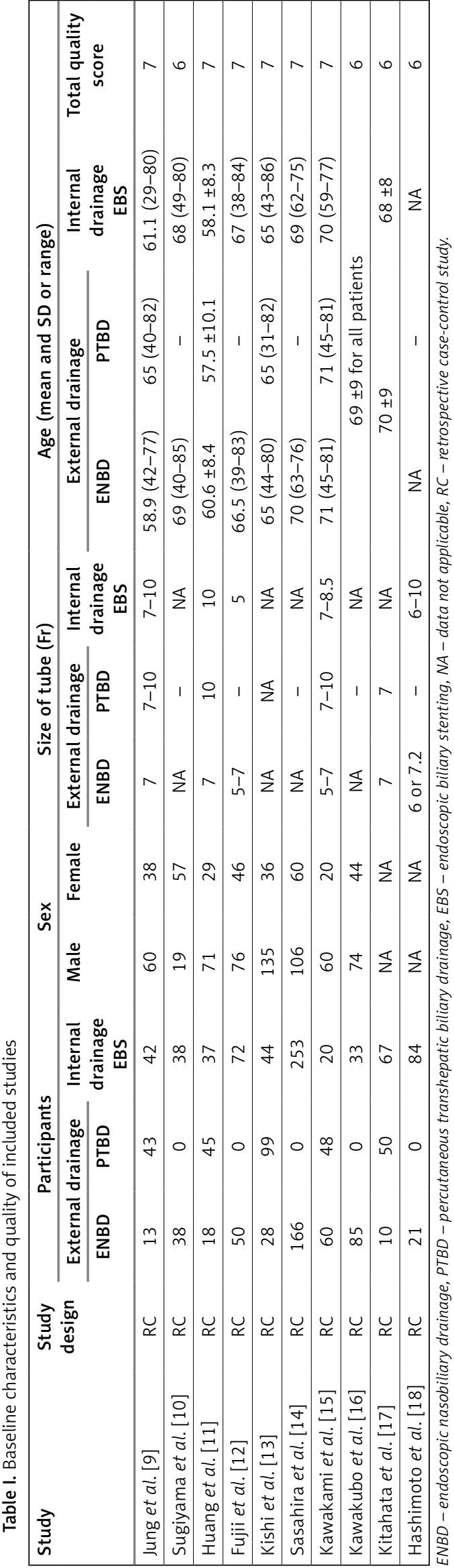

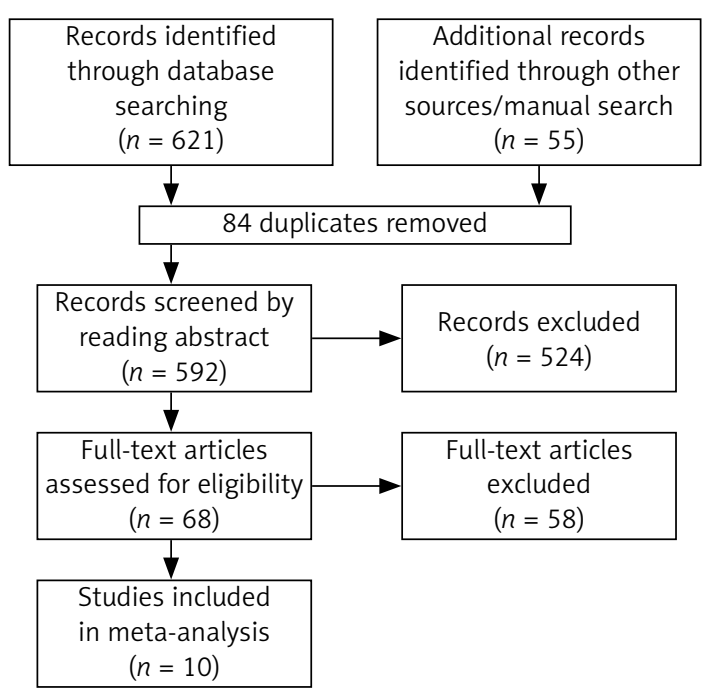

Figure 1. Flow chart for study selection

analysis; if there was significant heterogeneity $(p \leq 0.10)$, the random effects model was applied [6]. The level of heterogeneity between studies was evaluated using $l^{2}$ statistics. $I^{2}<30 \%$ was considered to be low heterogeneity, while $R^{2}>50 \%$ represented high heterogeneity. Sensitivity analysis was performed by removing 1 study at a time to assess whether the results would be markedly affected by a single study. Funnel plots were constructed to evaluate potential publication bias [7, 8]. The meta-analysis was performed on RevMan 5.3 (The Cochrane Collaboration, Oxford, UK) software provided by the Cochrane Collaboration.

\section{Results}

\section{Search results and study characteristics}

The last retrieval time was May 30, 2017. A total of 676 articles were retrieved by searching electronic databases and manually searching relevant reference lists. After duplicates were identified and excluded, 592 articles remained. We then excluded unrelated reviews, case reports, systematic reviews and meta-analyses, as well as studies that were clearly irrelevant based on their title or abstract. As a result, 68 articles remained. After reading the full text, 10 articles [9-18] involving a total of 1464 patients were included in the meta-analysis. The detailed steps of our document retrieval are shown in Figure 1. In total, 774 patients received external drainage, and 690 patients received internal drainage. All included articles are case-control studies. The characteristics of these studies are presented in Table I.

\section{Incidence of preoperative cholangitis}

Nine of the 10 studies [9-17], including 753 cases in the external drainage group and 606 cases in the internal drainage group, investigated preop- 


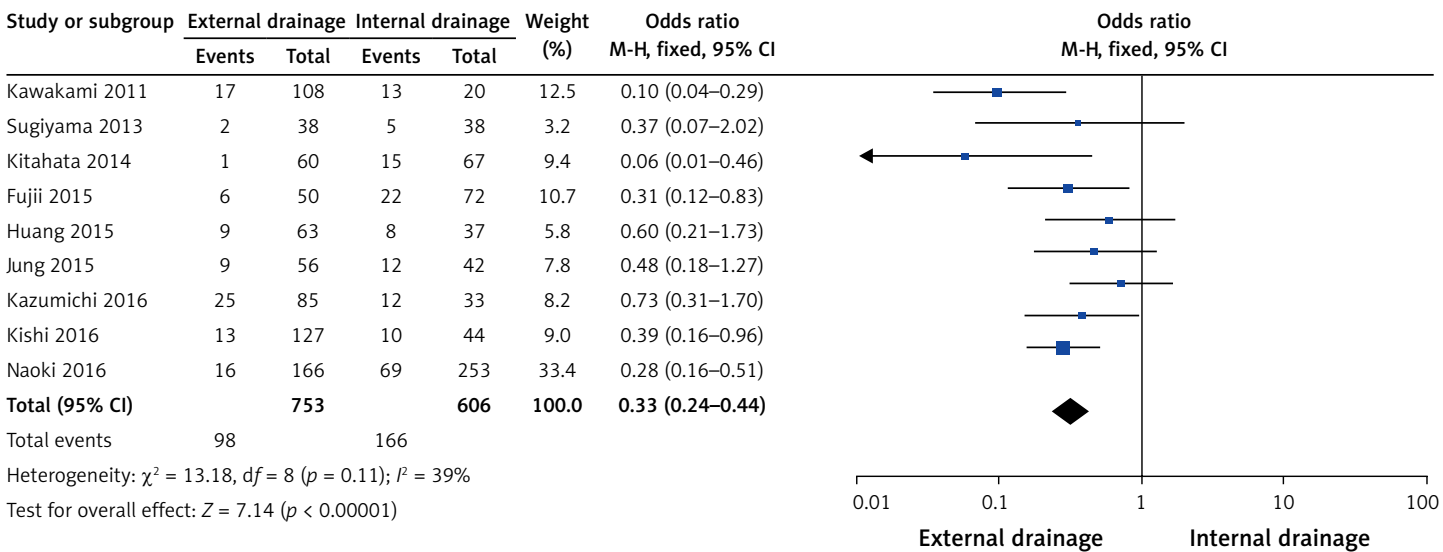

Figure 2. Forest plot of preoperative cholangitis rates

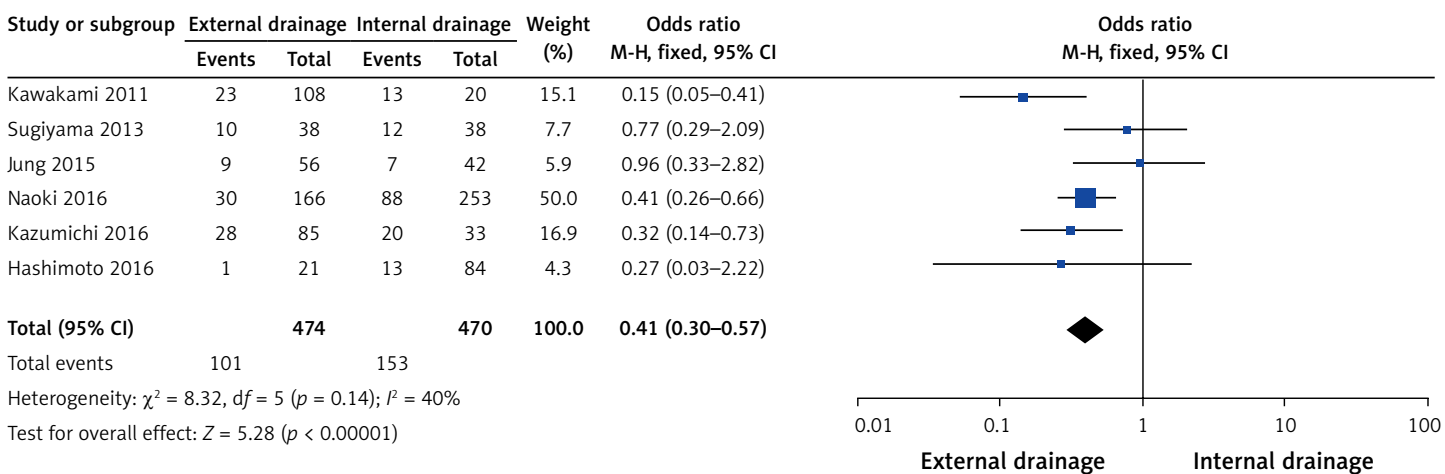

Figure 3. Forest plots of stent/tube dysfunction rate

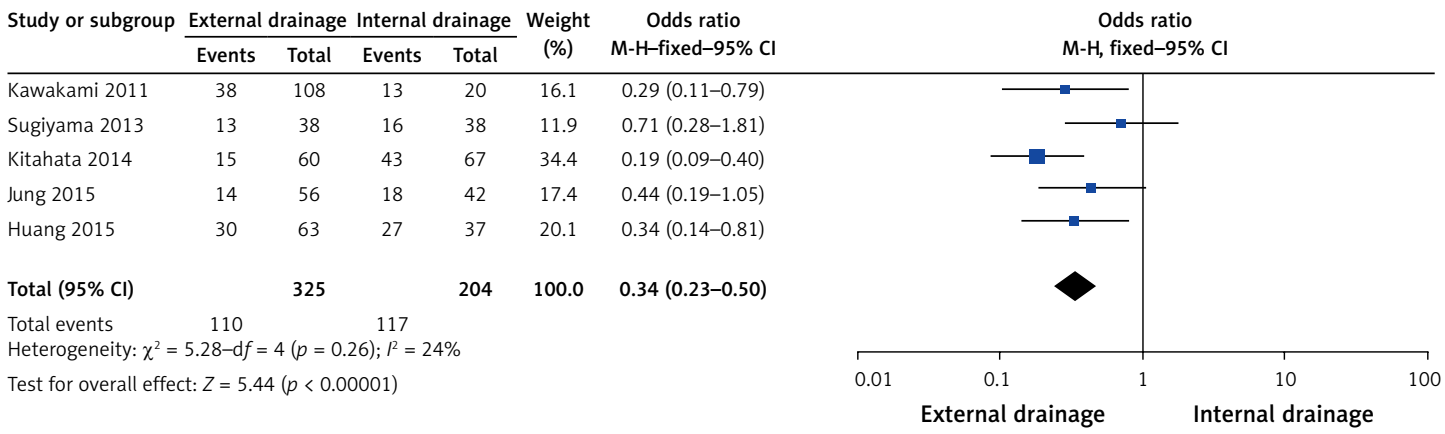

Figure 4. Forest plots of overall morbidity

erative cholangitis. The heterogeneity among the studies was not statistically significant $\left(I^{2}=39 \%\right.$, $p=0.11$ ), so we chose a fixed-effect model to pool the OR. Overall, the pooled data demonstrated that external drainage was associated with a low incidence of preoperative cholangitis $(O R=0.33$, $95 \% \mathrm{Cl}: 0.24-0.44, p<0.00001)$ in the MBO patients (Figure 2).

\section{Stent/tube dysfunction rate}

Six of the 10 studies [9, 10, 14-16, 18], including 474 cases in the external drainage group and 470 cases in the internal drainage group, reported a stent/tube dysfunction rate. Heterogeneity among studies was not statistically significant $\left(I^{2}=40 \%, p=0.14\right)$, so we chose a fixed-effect model to pool the OR. Overall, the pooled data demonstrated that external drainage was associated with a low incidence of stent/tube dysfunction (OR $=0.41,95 \% \mathrm{Cl}: 0.30-0.57, p<0.00001)$ in $\mathrm{MBO}$ patients (Figure 3).

\section{Overall morbidity}

Five of the 10 studies assessed overall morbidity $[9-11,15,17]$, which is defined as the incidence of all pre- and postoperative complications. Heterogeneity among them was not statistically significant $\left(R^{2}=24 \%, p=0.26\right)$. The pooled results 


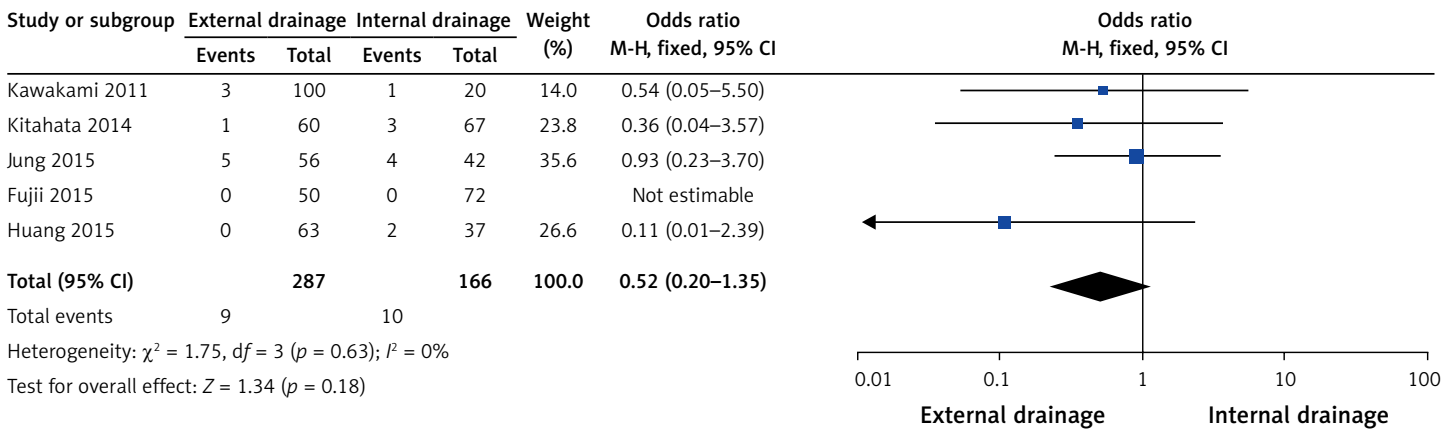

Figure 5. Forest plots of overall mortality

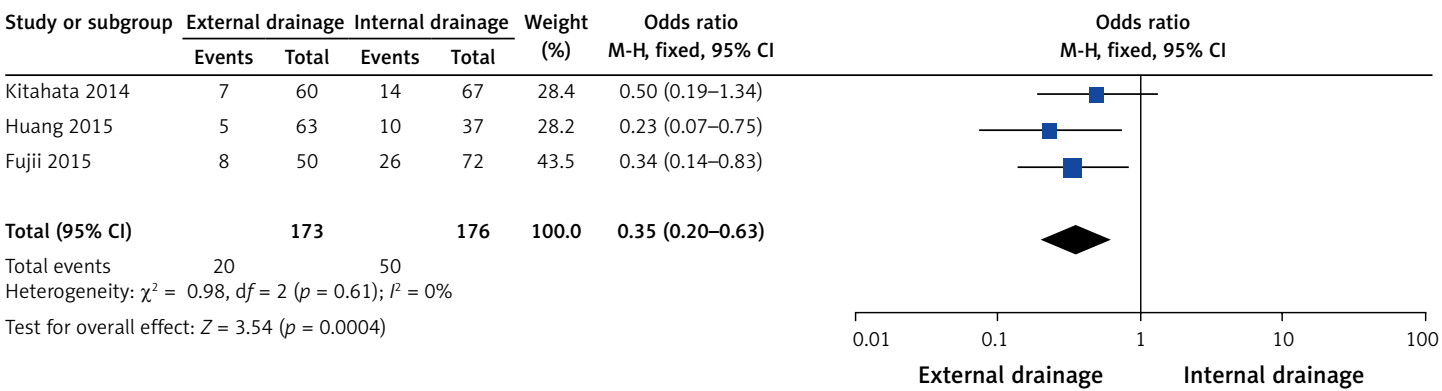

Figure 6. Forest plots of POPF

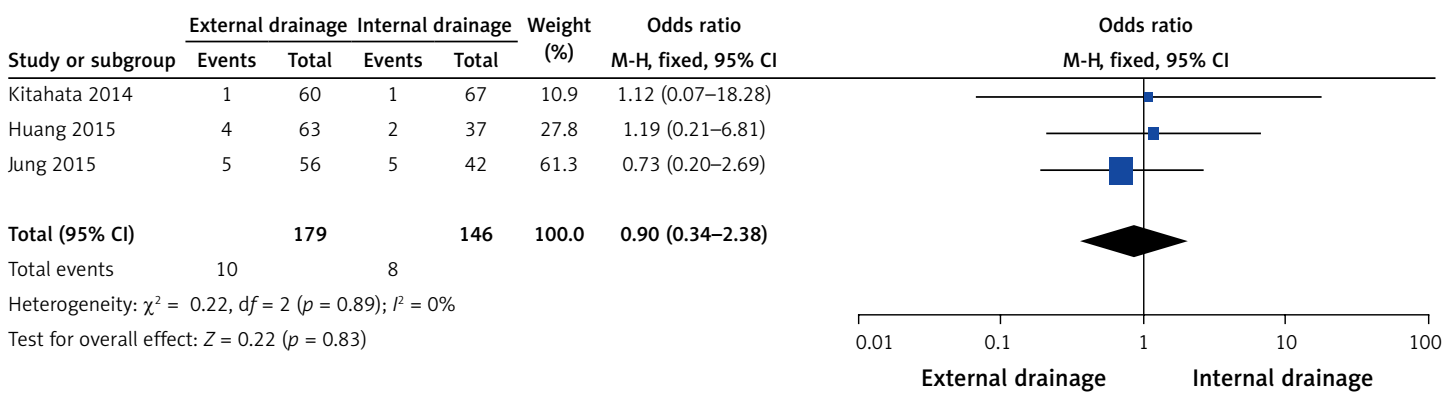

Figure 7. Forest plots of biliary leakage

showed that external drainage had a significantly lower incidence of morbidity than internal drainage $(\mathrm{OR}=0.34,95 \% \mathrm{Cl}: 0.23-0.50, p<0.00001)$ (Figure 4).

\section{Mortality}

Five of the 10 studies $[9,11,12,15,17]$ assessed mortality. No heterogeneity among them $\left(R^{2}=0 \%\right.$, $p=0.63$ ) was found, so we chose a fixed-effect model to pool the OR. Overall, the pooled data demonstrated that neither external drainage nor internal drainage was associated with significantly lower mortality $(\mathrm{OR}=0.52,95 \% \mathrm{Cl}$ : 0.20-1.35, $p=0.18$ ) in MBO patients (Figure 5).

\section{Postoperative pancreatic fistula}

Three of the 10 studies assessed the effect of postoperative pancreatic fistula (POPF) [11, 12, 17]. The pancreatic fistula rate was significantly lower in the external drainage group than in the internal drainage group $(\mathrm{OR}=0.35,95 \% \mathrm{Cl}: 0.2-0.63$, $p=0.0004$ ) based on the pooled data, which showed no heterogeneity $\left(R^{2}=0 \%, p=0.61\right)$ (Figure 6).

\section{Postoperative biliary leakage}

Three of the 10 studies investigated biliary leakage $[7,9,15]$. No heterogeneity $\left(R^{2}=0 \%, p=0.89\right)$ was found, so we chose a fixed-effect model to pool the OR. Overall, the pooled data demonstrated that neither external drainage nor internal drainage was associated with a significantly lower incidence of biliary leakage $(O R=0.90$, $95 \% \mathrm{Cl}: 0.34-2.38, p=0.83)$ in $\mathrm{MBO}$ patients (Figure 7).

\section{Intra-abdominal abscess}

Four of the 10 studies assessed the effect of intra-abdominal abscess $[9,11,12,17]$. Neither exter- 


\begin{tabular}{|c|c|c|c|c|c|c|c|c|c|c|}
\hline \multirow[t]{2}{*}{ Study or subgroup } & \multicolumn{4}{|c|}{ External drainage Internal drainage } & \multirow{2}{*}{$\begin{array}{l}\text { Weight } \\
(\%)\end{array}$} & \multirow{2}{*}{$\begin{array}{c}\text { Odds ratio } \\
\mathrm{M}-\mathrm{H} \text {, fixed, } 95 \% \mathrm{Cl}\end{array}$} & \multirow{2}{*}{\multicolumn{3}{|c|}{$\begin{array}{c}\text { Odds ratio } \\
M-H \text {, fixed, } 95 \% \mathrm{Cl}\end{array}$}} & \\
\hline & \multirow{2}{*}{$\begin{array}{c}\text { Events } \\
7\end{array}$} & \multirow{2}{*}{$\begin{array}{c}\text { Total } \\
60\end{array}$} & \multirow{2}{*}{$\frac{\text { Events }}{9}$} & \multirow{2}{*}{$\begin{array}{c}\text { Total } \\
67\end{array}$} & & & & & & \\
\hline Kitahata 2014 & & & & & 25.1 & $0.85(0.30-2.45)$ & & $\longrightarrow$ & - & \\
\hline Jung 2015 & 3 & 56 & 2 & 42 & 7.2 & $1.13(0.19-7.10)$ & & & & \\
\hline Fujii 2015 & 3 & 50 & 15 & 72 & 38.7 & $0.24(0.07-0.89)$ & & - & & \\
\hline Huang 2015 & 9 & 63 & 8 & 37 & 28.9 & $0.60(0.21-1.73)$ & & & & \\
\hline Total $(95 \% \mathrm{Cl})$ & & 229 & & 218 & 100.0 & $0.56(0.31-1.02)$ & & & & \\
\hline Total events & 22 & & 34 & & & & & & & \\
\hline Heterogeneity: $\chi^{2}=$ & $2.78, \mathrm{~d} f=$ & $3(p=0$ & 43); $1^{2}=0$ & & & & & & & \\
\hline Test for overall effec & ct: $Z=0.1$. & $0(p=0$ & & & & & 0.01 & 0.1 & 1 & 10 \\
\hline
\end{tabular}

Figure 8. Forest plots of intra-abdominal abscess

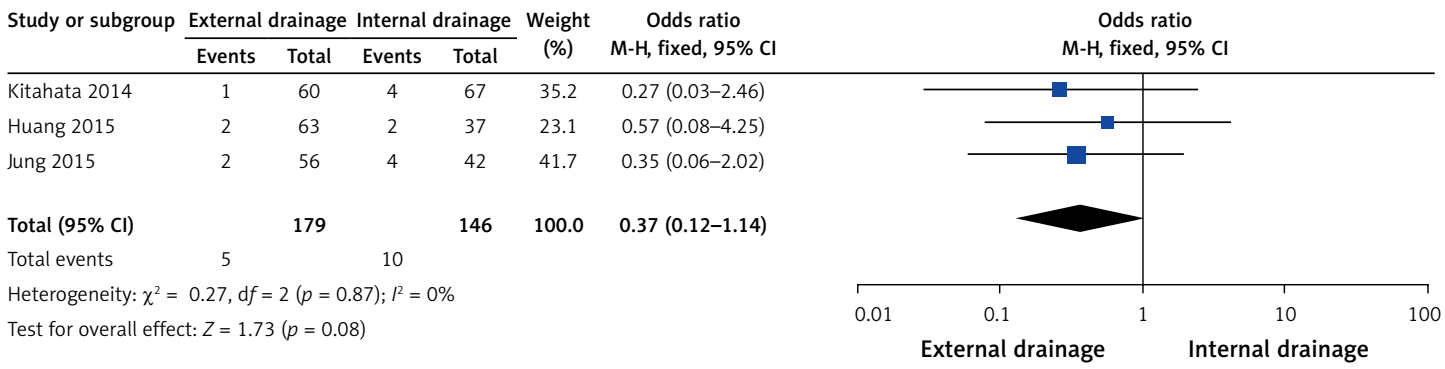

Figure 9. Forest plots of sepsis

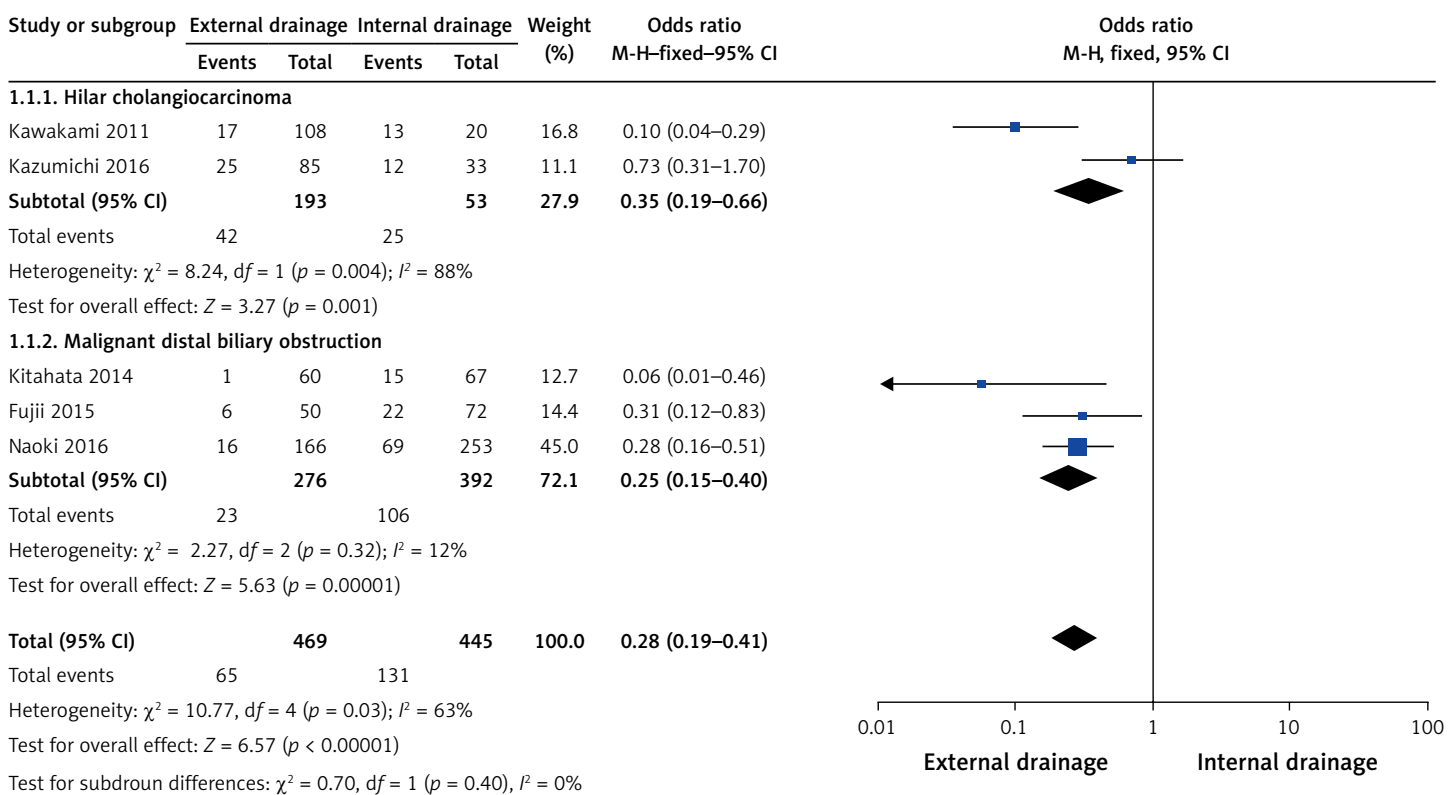

Figure 10. Forest plots of subgroup analysis of preoperative cholangitis

nal drainage nor internal drainage was associated with a significantly lower incidence of intra-abdominal abscess (OR $=0.56,95 \% \mathrm{Cl}$ : 0.31-1.02, $p=0.06)$ based on the pooled data, which showed no heterogeneity $\left(I^{2}=0 \%, p=0.43\right)$ (Figure 8).

\section{Postoperative sepsis}

Three of the 10 studies researched sepsis $[9,11,17]$. No heterogeneity $\left(l^{2}=0 \%, p=0.87\right)$ was found, so we chose a fixed-effect model to pool the OR. Overall, the pooled data demonstrated that neither external drainage nor internal drain- age was associated with a significantly lower incidence of sepsis (OR $=0.37,95 \% \mathrm{Cl}$ : $0.12-1.14$, $p=0.08$ ) in MBO patients (Figure 9).

\section{Subgroup analysis and sensitivity analysis}

Subgroup analysis showed a higher incidence of preoperative cholangitis in the internal drainage group than in the external drainage group among hilar cholangiocarcinoma (HCA) patients $(\mathrm{OR}=0.35,95 \% \mathrm{Cl}: 0.19-0.66, p=0.001)$ and malignant distal biliary obstruction patients $(\mathrm{OR}=0.25$, 95\% Cl: $0.15-0.40, p<0.00001$ ) (Figure 10). 


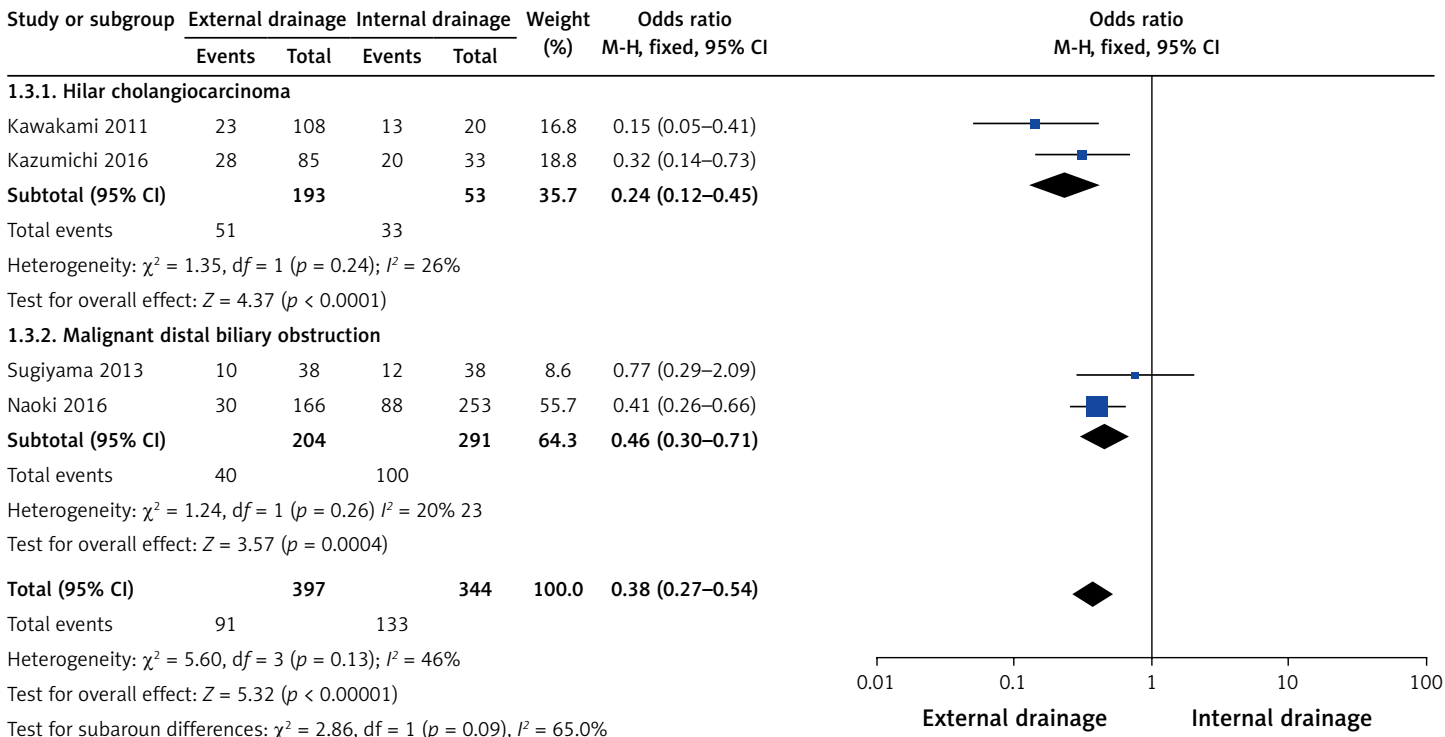

Test for subaroun differences: $\chi^{2}=2.86, \mathrm{df}=1(p=0.09), I^{2}=65.0 \%$

Figure 11. Forest plots of subgroup analysis of stent/tube dysfunction rate
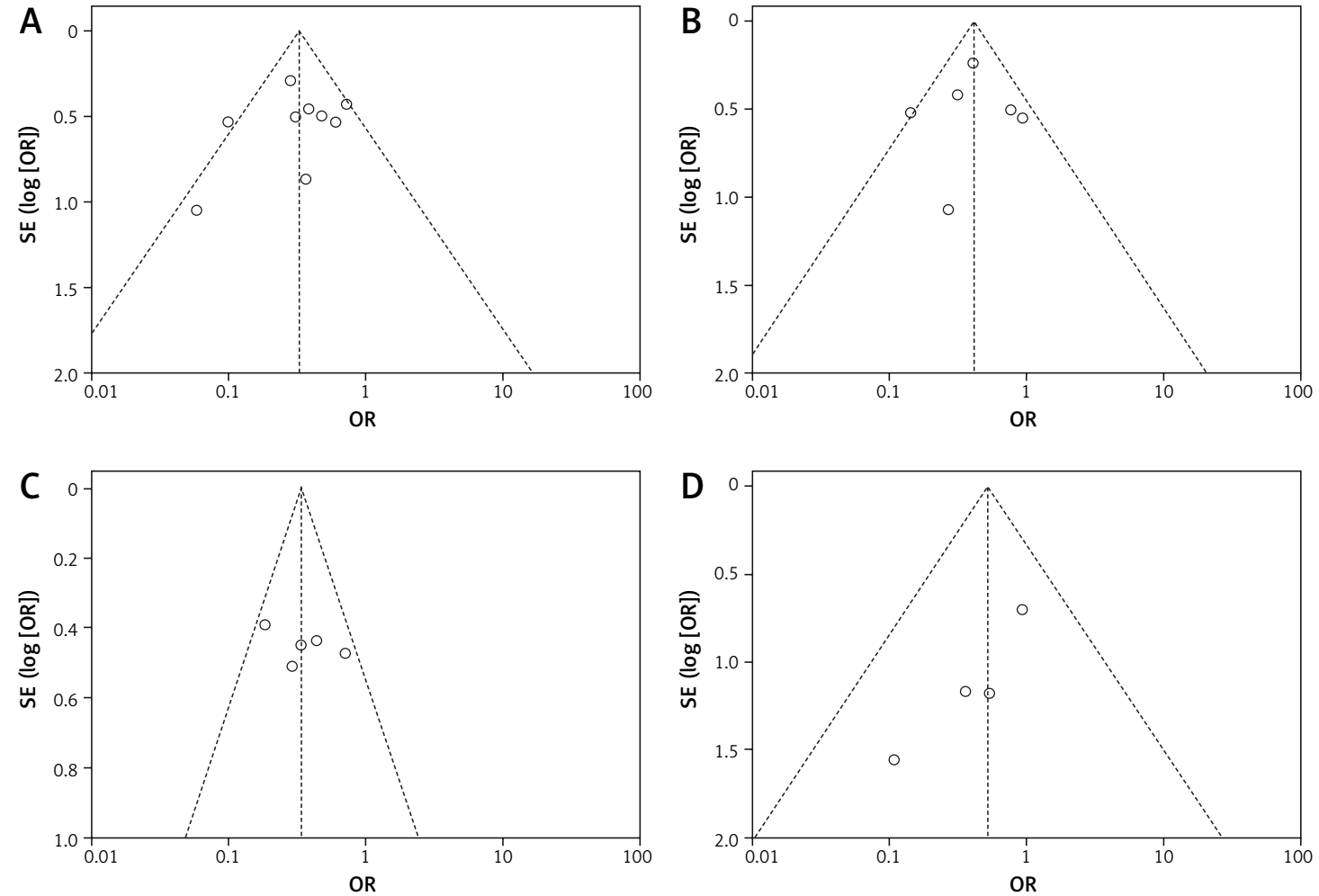

Figure 12. Funnel plot assessing for publication bias. A - preoperative cholangitis rate, B - stent/tube dysfunction rate, C - overall morbidity, D - mortality

The stent/tube dysfunction rate was also higher in the internal drainage group than in the external drainage group among HCA patients $(\mathrm{OR}=0.24,95 \% \mathrm{Cl}: 0.12-0.45, p<0.001)$ and malignant distal biliary obstruction patients $(\mathrm{OR}=0.46,95 \% \mathrm{Cl}: 0.30-0.71, p=0.0004)$ (Figure 11). Sensitivity analysis suggested that the data in this meta-analysis were relatively stable.

\section{Assessment of risk of bias}

Funnel plots for the preoperative cholangitis rate, the incidence of stent/tube dysfunction, overall morbidity and mortality were drawn (Figure 12). The publication bias was small because the points on the funnel plots were substantially symmetric. Funnel plots for POPF, biliary leak- 


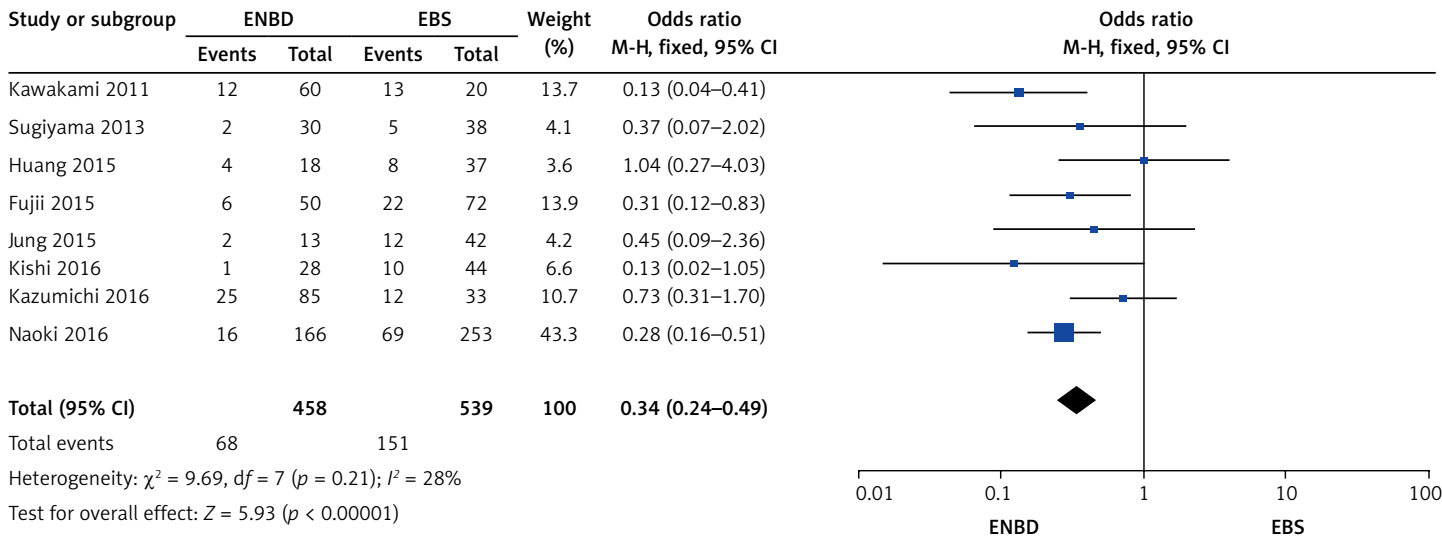

Figure 13. Forest plot of preoperative cholangitis in patients who underwent endoscopic internal and external drainage

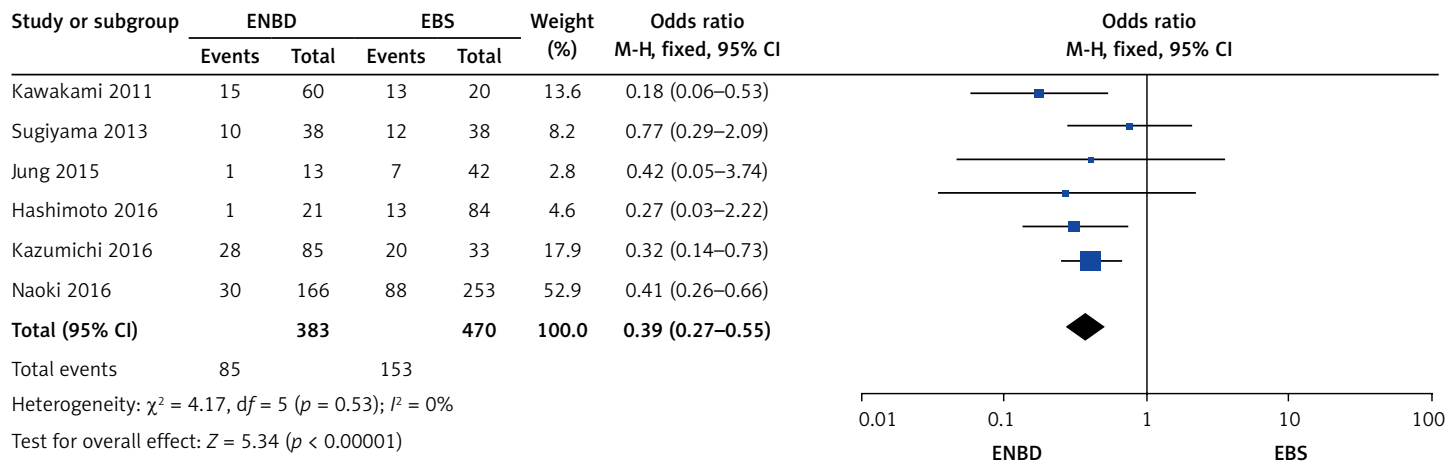

Figure 14. Forest plot of stent/tube dysfunction rate in patients who underwent endoscopic internal and external drainage

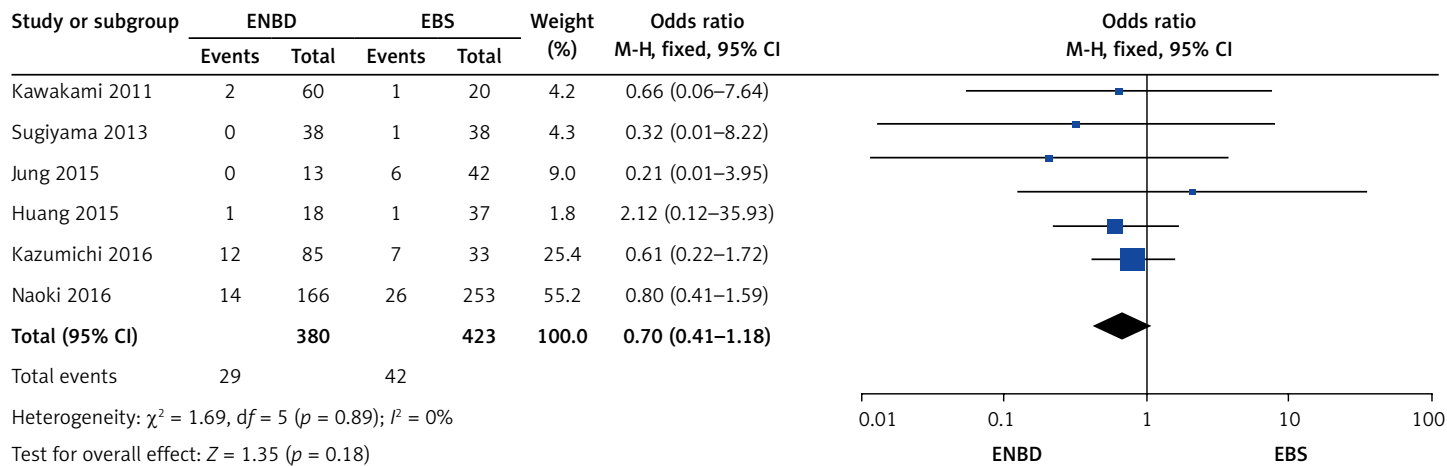

Figure 15. Forest plot of preoperative pancreatitis in patients who underwent endoscopic internal and external drainage

age, intra-abdominal abscess and sepsis were not made due to the small number of studies.

\section{The comparison of different ways of drainage in the endoscope}

A comparison was made separately between endoscopic internal and external drainage (EBS and ENBD), and the results indicated that ENBD was associated with a lower incidence of preoperative cholangitis $(\mathrm{OR}=0.34,95 \% \mathrm{Cl}$ : $0.24-0.49$, $p<0.00001$ ) in the MBO patients (Figure 13).
The stent/tube dysfunction rate was also lower in the ENBD group than in the EBS group $(\mathrm{OR}=0.39,95 \% \mathrm{Cl}: 0.27-0.55, p<0.00001)$ (Figure 14). Neither ENBD nor EBS was associated with a significantly lower incidence of preoperative pancreatitis (OR $=0.70,95 \% \mathrm{Cl}: 0.41-1.18$, $p=0.18$ ) in MBO patients (Figure 15). ENBD had a significantly lower incidence of morbidity than EBS (OR $=0.47,95 \% \mathrm{Cl}: 0.27-0.82, p=0.008)$ (Figure 16). Neither ENBD nor EBS was associated with a significantly lower mortality $(O R=0.26$, 95\% Cl: 0.04-1.6, $p=0.15$ ) (Figure 17). 


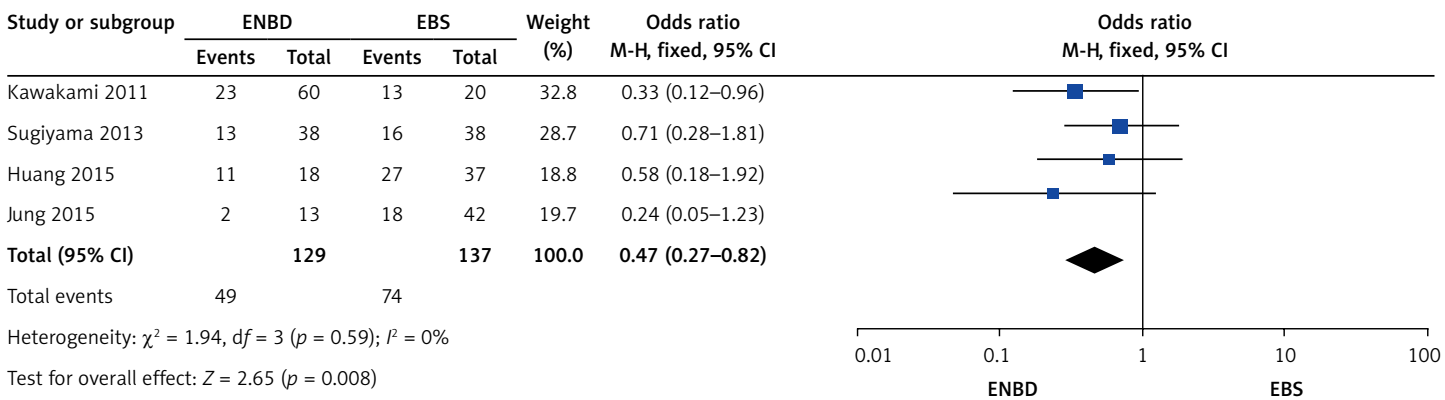

Figure 16. Forest plot of morbidity in patients who underwent endoscopic internal and external drainage

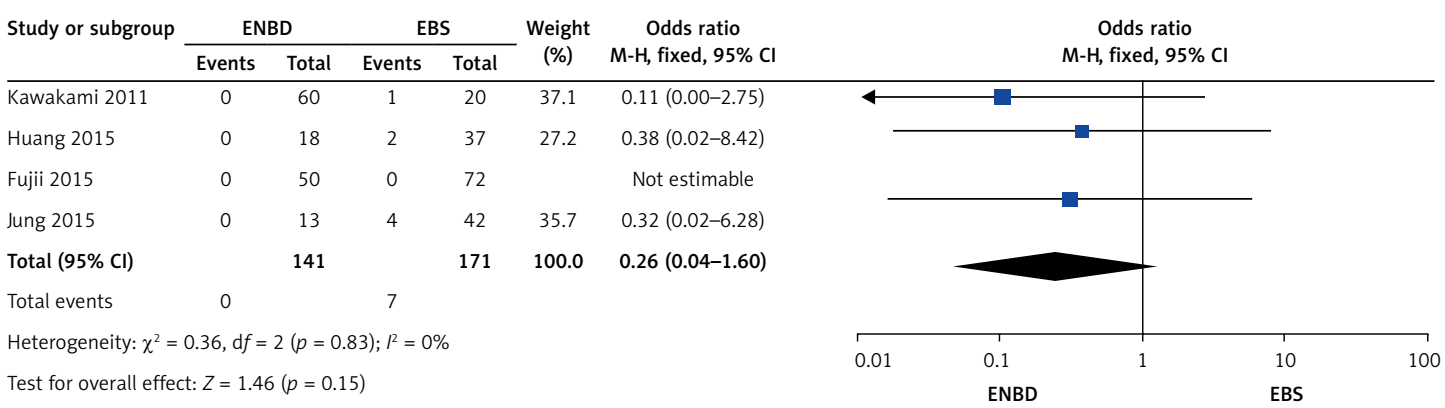

Figure 17. Forest plot of mortality in patients who underwent endoscopic internal and external drainage

\section{Discussion}

With the progress of technology, the success rate of surgical resection for malignant tumors of the biliary tract and pancreas head has become increasingly high. Nevertheless, the feasibility of surgery or other treatments depends not only on the TNM staging or the size of the tumor but also on the jaundice that arises from biliary obstruction, basic characteristics of patients, and other concomitant disease. According to the statistics, the postoperative mortality and postoperative morbidity of patients with malignant obstructive jaundice was $5 \%$ to $27 \%$ and $~ 50 \%$, respectively $[19,20]$. In consideration of the situation, a large number of studies have been carried out to explore the major risk factors causing the high mortality and morbidity. It has been reported that hyperbilirubinemia (serum bilirubin $\geq 170 \mathrm{mmol} / \mathrm{l}$ ) in patients who underwent obstructive jaundice surgery might increase their postoperative morbidity and mortality [21-23]. The reasons may be that hyperbilirubinemia would lead to impairment of liver function, decreased clearance of endotoxin, coagulation disorders, decreased immune function, and an impaired gastrointestinal mucosal barrier [24-27]. As an attempt to reduce these complications, preoperative biliary drainage was pursued in these patients. The aim was to restore normal physiology by improving the biliary drainage.

The EBS, PTBD and ENBD are the common drainage methods currently applied in the clinic. However, there is still no randomized controlled trial to evaluate which method is most ideal for preoperative drainage of malignant obstructive jaundice. This is the first meta-analysis to analyze whether internal drainage or external drainage is better for preoperative biliary drainage in patients with MBO. EBS has the advantages in cosmetic appeal and noninvasiveness [28], and, as a method of internal biliary drainage, it is more in compliance with human physiological needs, which may contribute to the improvement of nutritional status, reduction of endotoxemia, enhancement of the protective effect of the gastrointestinal mucosal barrier and improvement of the immune function [3]. Nevertheless, it has been reported that EBS may prolong hospital stay and increase postoperative morbidity and mortality compared with external drainage $[29,30]$. On the other hand, PTBD has a relatively low incidence of postoperative complications, and a higher rate of success than bile duct decompression with EBS for advanced hepatic hilar carcinoma [31]. As for ENBD, its advantage is that bile duct cytology and cholangiography can be performed simultaneously. However, external drainage has some disadvantages. For example, drains for external drainage may be dislodged or pulled out by patients when they are unconscious. Furthermore, PTBD is an invasive technique that involves catheterization into the parenchyma of the liver, which may increase the tumor spread to 5-20\% [32, 33], while ENBD may lead to patient discomfort or cosmetic problems because of the presence of the tube through the nasopharynx. 
In the present meta-analysis, the results showed that patients with malignant obstructive jaundice who received external drainage (PTBD or ENBD) had reductions in the preoperative cholangitis rate $(\mathrm{OR}=0.33,95 \% \mathrm{Cl}$ : 0.24-0.44, $p<0.00001)$, overall morbidity $(\mathrm{OR}=0.34$, 95\% Cl: 0.23-0.50, $p<0.00001)$ and postoperative complications in terms of pancreatic fistula $(\mathrm{OR}=0.35,95 \% \mathrm{Cl}: 0.2-0.63, p=0.0004)$ and intra-abdominal abscess (OR $=0.56,95 \% \mathrm{Cl}$ : $0.31-$ $1.02, p=0.06)$ than those who received internal drainage (EBS). The stents used for EBS, which connect the biliary tract and the duodenum, could become clogged due to intestinal microbes and reverse the flow of food when used for distal malignant obstruction. This is not only one of the reasons why biliary tract infections and preoperative cholangitis occur but also a potential risk of postoperative infectious complications [12]. This meta-analysis showed that stent dysfunction occurred more often in the internal group $(\mathrm{OR}=$ $0.39,95 \% \mathrm{Cl}: 0.28-0.56, p<0.0001)$ than in the external group, and that the causes of dysfunction were stent occlusion in EBS and dislocation in ENBD or PTBD [15]. Stent occlusion was reported to cause more than half the incidence of preoperative cholangitis [34]. Furthermore, some previous studies have confirmed that occurrence of preoperative cholangitis significantly increased postoperative complications including pancreatic fistula and delayed gastric emptying $[35,36]$. Therefore, internal drainage, which was associated with more preoperative cholangitis, significantly increased the incidence of morbidity compared with external drainage. However, there was no significant difference in in-hospital mortality between external drainage and internal drainage $(\mathrm{OR}=0.52,95 \% \mathrm{Cl}: 0.20-1.35, p=0.18)$. In addition, subgroup analyses were conducted. The results also showed that in both HCA patients and those with malignant distal biliary obstruction, the incidence of preoperative cholangitis and the rate of stent dysfunction with internal drainage were higher than those with external drainage. Other aspects, such as overall morbidity, were not further analyzed due to the limited number of selected articles. Therefore, the results of the subgroup analyses suggest that the location and type of tumor do not affect our conclusion that external drainage is better than internal drainage for malignant biliary obstruction in terms of the incidence of preoperative cholangitis and the rate of stent dysfunction.

At the same time, a single comparison was also made between the two methods of endoscopic internal and external drainage (EBS and ENBD), and the results also suggested that patients with malignant obstructive jaundice who received ENBD had a lower preoperative cholangitis rate $(O R=0.34$, 95\% Cl: $0.24-0.49, p<0.00001)$, stent/tube dysfunction rate $(\mathrm{OR}=0.39,95 \% \mathrm{Cl}: 0.27-0.55$, $p<0.00001)$ and overall morbidity $(\mathrm{OR}=0.47$, $95 \% \mathrm{Cl}: 0.27-0.82, p=0.008)$ than those who received EBS. In addition, the incidence of preoperative pancreatitis (OR $=0.70,95 \% \mathrm{Cl}: 0.41-1.18, p=$ 0.18 ) was higher in the EBS group than in the ENBD group even though the meta-analysis showed no significant difference. A prospective study [37] showed that EBS was one of the factors that cause pancreatitis. Stent placement, especially a largebore stent, would cause the obstruction of the adjacent pancreatic orifice, and limit the outflow of pancreatic juice, which may be a potential risk factor to induce pancreatitis. In addition, an endoscopic sphincterotomy is usually performed when large-bore plastic stents are placed. Perforations, ulcers, and stent dysfunction caused by endoscopic sphincterotomy are always associated with pancreatitis and other complications.

In conclusion, external drainage is superior to internal drainage for malignant biliary obstruction in controlling preoperative and postoperative complications according to this meta-analysis. However, long-term external drainage can lead to insufficient bile in the intestines, thus weakening inhibition of intestinal bacteria and causing endotoxemia [23]. It may also cause malnutrition because of lipid malabsorption and fluid balance disorders because of bile loss. These problems of external drainage may be solved by internal drainage. In humans, it is well known that the increased intestinal permeability caused by obstructive jaundice is recovered after internal biliary drainage [38, 39]. Internal drainage is more physiological than external drainage, as the enterohepatic circulation of bile is maintained. The benefits of internal drainage have been demonstrated in a series of animal experiments conducted by our team concerning internal and external drainage for the management of obstructive jaundice [40-42]. Our results indicated that internal drainage was superior to external drainage in restoring the damaged intestinal barrier, inhibiting bacterial translocation and reducing expression of inflammatory factors. Nevertheless, the advantages of internal drainage relative to external drainage were not demonstrated in the current meta-analysis or in the included studies. One of the possible reasons is that, due to the limited clinical drainage technique, plastic stents were predominantly used in the involved patients who underwent internal drainage. Plastic stents are inexpensive and easy to operate for repeated placement; however, their major disadvantage is that they may lead to recurrence of jaundice and increase the incidence of cholangitis [43-45]. Compared with 
plastic stents, metal stents have a larger diameter when expanded, and the expansion time is notably longer [46-48]. Wasan et al. [49] showed that metal stents could reduce the occurrence of cholangitis and intraoperative and postoperative complications. Moreover, covered metallic stents may not only protect against tumor ingrowth but also minimize bacterial adherence and sludge formation that cause biliary infections $[50,51]$. How ever, the high price has limited the widespread use of metal stents in clinical practice. Therefore, research and literature on the use of metal stents in internal drainage is insufficient.

In addition to the absence of metal stents included as a comparative study, other limitations should also be taken into account in the meta-analysis. Firstly, the studies were all retrospective studies lacking randomized controlled trials. Secondly, the number of studies included and subgroup analysis were inadequate. Thirdly, different studies defined the complications differently, and the evaluation criteria were different, which might affect the final analysis. With respect to the above, large-scale, large-sample, multi-centered and randomized controlled trials will be needed to further validate the results.

\section{Conflict of interest}

The authors declare no conflict of interest.

\section{References}

1. Moole H, Bechtold ML, Forcione D, Puli SR. A meta-analysis and systematic review: success of endoscopic ultrasound guided biliarystenting in patients with inoperable malignant biliary strictures and a failed ERCP. Medicine 2017; 96: e5154.

2. Coates JM, Beal SH, Russo JE, et al. Negligible effect of selective preoperative biliary drainage on perioperative resuscitation, morbidity, and mortality in patients undergoing pancreaticoduodenectomy. Arch Surg 2009; 144: 841-7.

3. Sewnath ME, Karsten TM, Prins MH, Rauws EJA, Obertop H, Gouma DJ. A meta-analysis on the efficacy of preoperative biliary drainage for tumors causing obstructive jaundice. Ann Surg 2002; 236: 17-27.

4. Fang Y, Gurusamy KS, Wang Q, et al. Preoperative biliary drainage for obstructive jaundice. Cochrane Database Syst Rev 2012; 12: CD005444.

5. Martin B, Paesmans M, Berghmans T, et al. Role of Bcl-2 as a prognostic factor for survival in lung cancer: a systematic review of the literature with meta-analysis. $\mathrm{Br}$ J Cancer 2003; 89: 55-64.

6. Moćko P, Kawalec P, Smela-Lipińska B, et al. Effectiveness and safety of vedolizumabfor treatment of Crohn's disease: a systematic reviewand meta-analysis. Arch Med Sci 2016; 12: 1088-96.

7. Sterne JAC, Egger M, Davey-Smith G. Investigating and dealing with publication and other biases in meta-analysis. Br Med J 2001; 323: 101-5.

8. Sterne JAC, Egger M. Funnel plots for detecting bias in meta-analysis: guidelines on choice of axis. J Clin Epidemiol 2001; 54: 1046-55.
9. Jung JH, Chung MJ, Han DH, et al. Best options for preoperative biliary drainage in patients with Klatskin tumors. Surg Endosc 2016; 31: 422-9.

10. Sugiyama H, Tsuyuguchi T, Sakai Y, Nisikawa T, Miyazaki M, Yokosuka O. Preoperative drainage for distal biliary obstruction: endoscopic stenting or nasobiliary drainage? Hepatogastroenterology 2013; 60: 231-4.

11. Huang $X$, Liang $B$, Zhao XO, Zhang FB, Wang XT, Dong $\mathrm{JH}$. The effects of different preoperative biliary drainage methods on complications following pancreaticoduodenectomy. Medicine 2015; 94: e723.

12. Fujii T, Yamada $S$, Suenaga $M$, et al. Preoperative internal biliary drainage increases the risk of bile juice infection and pancreatic fistula after pancreatoduodenectomy a prospective observational study. Pancreas 2015; 44: 465-70.

13. Kishi Y, Shimada K, Nara S, Esaki M, Kosuge T. The type of preoperative biliary drainage predicts short-term outcome after major hepatectomy. Langenbecks Arch Surg 2016; 401: 503-11.

14. Sasahira N, Hamada T, Togawa O, et al. Multicenter study of endoscopic preoperative biliary drainage for malignant distal biliary obstruction. World J Gastroenterol 2016; 22: 3793-802.

15. Kawakami H, Kuwatani M, Onodera M, et al. Endoscopic nasobiliary drainage is the most suitable preoperative biliary drainage method in the management of patients with hilar cholangiocarcinoma. J Gastroenterol 2011; 46: 242-8.

16. Kawakubo K, Kawakami H, Kuwatani M, et al. Endoscopic nasobiliary drainage has lower incidence of complications than endoscopic biliary stenting for the management of hilar cholangiocarcinoma. J Gastroenterol Hepatol 2015; 30: 235.

17. Kitahata Y, Kawai M, Tani M, et al. Preoperative cholangitis during biliary drainage increases the incidence of postoperative severe complications after pancreaticoduodenectomy. Am J Surg 2014; 208: 1-10.

18. Hashimoto S, Ito K, Koshida S, et al. Risk factors for post-endoscopic retrograde cholangiopancreatography (ERCP) pancreatitis and stent dysfunction after preoperative biliary drainage in patients with malignant biliary stricture. Intern Med 2016; 55: 2529-36.

19. Lai EC, Chu KM, Lo CY, et al. Surgery for malignant obstructive jaundice: analysis of mortality. Surgery 1992; 112: 891-6.

20. Karsten T, Allema J, Reinders M, et al. Preoperative biliary drainage, colonisation of bile and postoperative complications in patients with tumours of the pancreatic head: a retrospective analysis of 241 consecutive patients. Eur J Surg 1996; 162: 881-8.

21. Bhati CS, Kubal C, Sihag PK, et al. Effect of preoperative biliary drainage on outcome of classical pancreaticoduodenectomy. World J Gastroenterol 2007; 13: 1240.

22. Peskova M, Gurlich R. Preoperative biliary drainage before pancreatoduodenectomy in patients with obstructive jaundice. Eur Surg 2005; 37: 331-5.

23. Sewnath ME, Birjmohun RS, Rauws EA, Huibregtse K, Obertop H, Gouma DJ. The effect of preoperative biliary drainage on postoperative complications after pancreaticoduodenectomy. J Am Coll Surg 2001; 192: 726-34.

24. Ljungdahl M, Osterberg J, Ransjö U, Engstrand L, Haglund U. Inflammatory response in patients with malignant obstructive jaundice. Scand J Gastroenterol 2007; 42: 94-102.

25. Waqar SH, Malik ZI, Razzaq A, Abdullah MT, Shaima A, Zahid MA. Frequency and risk factors for wound dehis- 
cence burst abdomen in midline laparotomies. J Ayub Med Coll Abbottabad 2005; 17: 70-3.

26. Assimakopoulos SF, Scopa CD, Zervoudakis G, et al. Bombesin and neurotensin reduce endotoxemia, intestinal oxidative stress, and apoptosis in experimental obstructive jaundice. Ann Surg 2005; 241: 159-67.

27. Papadopoulos V, Filippou D, Manolis E, et al. Haemostasis impairment in patients with obstructive jaundice. J Gastrointestin Liver Dis 2007; 16: 177-86.

28. Kim KM, Park JW, Lee JK, et al. A comparison of preoperative biliary drainage methods for perihilar cholangiocarcinoma: endoscopic versus percutaneous transhepatic biliary drainage. Gut Liver 2015; 9: 791-9.

29. Kloek JJ, van der Gaag NA, Aziz Y, et al. Endoscopic and percutaneous preoperative biliary drainage in patients with suspected hilar cholangiocarcinoma. J Gastrointest Surg 2010; 14: 119-25.

30. Rerknimitr R, Kladcharoen N, Mahachai V, Kullavanijaya P. Result of endoscopic biliary drainage in hilar cholangiocarcinoma. J Clin Gastroenterol 2004; 38: 518-23.

31. Paik WH, Loganathan N, Hwang JH. Preoperative biliary drainage in hilar cholangiocarcinoma: When and how? World J Gastrointest Endosc 2014; 6: 68-73.

32. Sakata J, Shirai Y, Wakai T, et al. Catheter tract implantation metastases associated with percutaneous biliary drainage for extrahepatic cholangiocarcinoma. World J Gastroenterol 2005; 11: 7024-7.

33. Gerhards MF, Gonzalez DG, ten Hoopen-Neumann $\mathrm{H}$, van Gulik TM, de Wit LT, Gouma DJ. Prevention of implantation metastases after resection of proximal bile duct tumours with pre-operative low dose radiation therapy. Eur J Surg Oncol 2000; 26: 480-5.

34. van der Gaag NA, Rauws EAJ, van Eijck CHJ, et al. Preoperative biliary drainage for cancer of the head of the pancreas. N Engl J Med 2010; 362: 129-37.

35. Park YC, Kim SW, Jang JY, et al. Factors influencing delayed gastric emptying after pylorus-preserving pancreatoduodenectomy. J Am Coll Surg 2003; 196: 859-65.

36. Sohn TA, Yeo CJ, Cameron JL, et al. Do preoperative biliary stents increase postpancreaticoduodenectomy complications? J Gastrointest Surg 2000; 4: 258-67.

37. Wilcox CM, Phadnis M, Varadarajulu S. Biliary stent placement is associated with post-ERCP pancreatitis. Gastrointest Endosc 2010; 72: 546-50.

38. Diamond T. Intestinal barrier dysfunction in clinical and experimental obstructive jaundice and its reversal by internal biliary drainage. Br J Surg 1996; 83: 1345-9.

39. Welsh FKS, Ramsden CW, MacLennan K, et al. Increased intestinal permeability and altered mucosal immunity in cholestatic jaundice. Ann Surg 1998; 227: 205-12.

40. Wang ZK, Xiao JG, Li W, et al. Effect of biliary drainage on inducible nitric oxide synthase, CD14 and TGR5 expression in obstructive jaundice rats. World J Gastroenterol 2013; 19: 2319-30.

41. Wu L, Li W, Wang Z. Bile acid-induced expression of farnesoid $X$ receptor as the basis for superiority of internal biliary drainage in experimental biliary obstruction. Scand J Gastroenterol 2013; 48: 496-503.

42. Meng Y, Gong YC, Dou Y, Li W. Changes of serum cytokines and expression of inducible nitric oxide synthase mRNA by Kupffer cells after relief from obstructive jaundice in rats. J Gastroenterol Hepatol 2009; 24: 1064-9.

43. Cipolletta L, Rotondano G, Marmo R, Bianco MA; Italian Evidence-Based Gastroenterology \& Hepatology Club. Endoscopic palliation of malignant obstructive jaundice: an evidence-based review. Dig Liver Dis 2007; 39: 375-88.
44. Costamagna G, Pandolfi M. Endoscopic stenting for biliary and pancreatic malignancies. J Clin Gastroenterol 2004; 38: 59-67.

45. Siddiqui AA, Sreenarasimhaiah J, Lara LF, et al. Endoscopic ultrasound-guided transduodenal placement of a fully covered metal stent for palliative biliary drainage in patients with malignant biliary obstruction. Surg Endosc 2011; 25: 549-55.

46. Davids PH, Groen AK, Rauws E, Tytgat GN, Huibregtse K. Randomised trial of self-expanding metal stents versus polyethylene stents for distal malignant biliary obstruction. Lancet 1992; 340: 1488-92.

47. Knyrim K, Wagner H, Pausch J, Vakil N. A prospective, randomized, controlled trial of metal stents for malignant obstruction of the common bile duct. Endoscopy 1993; 25: 207-12.

48. Prat F, Chapat O, Ducot B, et al. A randomized trial of endoscopic drainage methods for inoperable malignant strictures of the common bile duct. Gastrointest Endosc 1998; 47: 1-7.

49. Wasan SM, Ross WA, Staerkel GA, et al. Use of expandable metallic biliary stents in resectable pancreatic cancer. Am J Gastroenterol 2005; 100: 2056-61.

50. Kahaleh M, Tokar J, Conaway MR, et al. Efficacy and complications of covered Wallstents in malignant distal biliary obstruction. Gastrointest Endosc 2005; 61: 528-33.

51. Soderlund C, Linder S. Covered metal versus plastic stents for malignant common bile duct stenosis: a prospective, randomized, controlled trial. Gastrointest Endosc 2006; 63: 986-95. 